\title{
GCU
}

Glasgow Caledonian

University

University for the Common Good

\section{The development of service provider's BPO-IT framework}

Ikerionwu, Charles; Edgar, David; Gray, Edwin

Published in:

Business Process Management Journal

DOI:

10.1108/BPMJ-10-2015-0146

Publication date:

2017

Document Version

Author accepted manuscript

Link to publication in ResearchOnline

Citation for published version (Harvard):

Ikerionwu, C, Edgar, D \& Gray, E 2017, 'The development of service provider's BPO-IT framework', Business Process Management Journal, vol. 23, no. 5, pp. 897-917. https://doi.org/10.1108/BPMJ-10-2015-0146

\section{General rights}

Copyright and moral rights for the publications made accessible in the public portal are retained by the authors and/or other copyright owners and it is a condition of accessing publications that users recognise and abide by the legal requirements associated with these rights.

Take down policy

If you believe that this document breaches copyright please view our takedown policy at https://edshare.gcu.ac.uk/id/eprint/5179 for details of how to contact us. 


\title{
The Development of Service provider's BPO-IT framework
}

\author{
Abstract \\ Purpose - The decision to operate BPO-IT organisational model by a BPO service provider \\ has far reaching benefits. This paper develops a service provider's BPO-IT framework that \\ provides in-house IT function (software) required to process client services. \\ Design/methodology/approach - The multi-case study adopted an exploratory sequential \\ mixed method research approach. In the first instance, 7 BPO service provider organisations \\ were investigated in the qualitative phase and 156 in the quantitative phase respectively. \\ Findings - The adoption of the developed framework indicates that it could reduce failures \\ in BPO relationships through reduced turnaround time in processing client services, \\ improved quality of service, reduced cost, improved client and provider's competitiveness, \\ and confidentiality of client operations. Outsourcing clients could lay the foundation for a \\ successful relationship by adopting a selection process that could choose the right provider. \\ Originality/value - The paper reveals BPO-IT organisation's operation towards in-house \\ provision of software required to process client services. A research exploring BPO service \\ providers from a top outsourcing destination like India could provide offshore outsourcing \\ clients the information to move towards onshore outsourcing. \\ Keywords - Software, BPO-IT, Outsourcing, IT management \\ Paper type - Research paper
}

\section{Introduction}

Business Process Outsourcing (BPO) has been a popular form of outsourcing, with IT as integral to the process and management (Lacity and Willcocks, 2012; Mani et al., 2010) and involving the provision of infrastructure to support functions both at the client and service provider's level (Loh and Venkatraman, 1992; Mani et al., 2006). A service provider can either obtain the IT function from an IT company through subcontracting or develop it inhouse thus integrating IT into their organisation. According to Feeny et al. (2005), outsourcing clients tend to choose a service provider that can provide both the business 
services and the required IT functions through in-house as part of their contract provision. In effect, improving performance through synergistic advantages.

While beneficial, BPO is not without risks or failure. In order to reduce failure in BPO relationships and improve performance (Willcocks, 2010), there have been suggestions for service provider organisations to invest in IT infrastructure (Click and Duening, 2005; Linder et al., 2002; Weerakkody et al., 2003), this allows required IT functions to be provided within the BPO service provider organisation. Thus, the BPO service provider will, in addition to the services, provide the IT functions required to process and deliver client services. Specific components suggested within the IT infrastructure include IT managerial skills, information and communication technology and application software development provision (Karmakar, 2004; Bharadwaj and Saxena, 2009). In the past, Kraut and Streeter (1995) had identified the quality of application software used in processing services as a key IT component for determining the quality of services delivered to clients. This implies that the development process of software could impact on its quality and therefore quality of services delivered to clients. As Michell and Fitzgerald (1997) suggested, the development of the application software within the service provider organisation could improve the quality of the software because of the provider's understanding of their domain's requirements (e.g. financial services domain), thus improving quality of services delivered to clients.

In line with suggestions made for service providers to invest and integrate IT infrastructure, both practitioners and academics (Weerakkody et al., 2003; Singh, 2012) suggest a distinctive BPO-IT organisational model, whereby a BPO service provider would provide the IT functions required to process and deliver client services. For the purpose of clarity, in this study, BPO service provider organisations practicing this model are called BPO-IT organisations. In some literature, these organisations are also referred to as IT-BPO organisations. In addition, "process" and "service" are interchangeably used - a service comprises of different processes. For example, a financial service outsourced by a client could include processes such as database management for profiling customers, accounting and daily transaction software. While existing research has explored the nature of BPO-IT organisations, there is currently a lack of research into understanding the approach for service provider organisations to operate a BPO-IT organisational model. This paper therefore offers a framework for BPO-IT development which, when developed, could define 
a software development process that can provide application software with an acceptable level of quality to process client's services. This offers greater efficiency, effectiveness and efficacy for organisations and improves their competitiveness.

While Kremic et al. (2006) demonstrated the process of outsourcing through the development of an outsourcing decision framework; Fjermestad and Saitta (2005) developed an IT outsourcing framework. Research is generally limited and in both cases, the authors suggest the need for further research to identify and address the specific IT components within the framework that would support decision making in outsourcing. Gyeung-Min (2008) identified IT maturity as a key factor for value creation while Bharadwaj and Saxena (2009), in their study - "building wining relationship in business process outsourcing services" demonstrated the effectiveness of a robust and scalable technology, and knowledgeable people towards delivery of services. In another instance, Mahmoodzadeh et al. (2009) developed a general BPO framework based on business process and knowledge managements, which focused on reducing the risks and pitfalls associated with outsourcing. Therefore, our paper will, through the adoption of mixed method research, develop a specific BPO-IT framework for service provider organisations seeking to operate a BPO-IT organisational model. To do so, the paper explores decision factors relating to BPO service provision, the outsourcing process cycle and reasons for operating BPO operational models. Emphasis is on in-house software development processes. Our paper is divided into sections: the introduction, which defines the nature of the research problem; background of study, exploring the theoretical underpinning to our proposed BPO-IT framework; research methodology for conducting the study; findings and discussion of our framework; and limitations and further research.

\section{Background}

Outsourcing is a global phenomenon and a key corporate tool in business. As such, researchers have provided different reasons why organisations outsource, these range from cost reduction and improving productivity, to availing the best skills, and remaining competitive, justifying every aspect of the outsourcing engagement (Willcocks et al., 2010; Lacity et al., 2011). However, outsourcing is not without risks and clients that overlook this aspect could experience unsuccessful relationship. Many organisations have failed to realise 
their outsourcing objectives because of poor evaluation of the right activity or process to outsource (Mclvor et al., 2010). Specifically, BPO is associated with known disadvantages, which include erosion of knowledge and expertise within the outsourcing client; valuable data could fall into the hand of competitors, and loss of management control (Yang et al., 2007). Further, table 1 presents type of risks and its components associated with outsourcing.

\section{$====$ Table $1===$}

Aron et al. (2005) identified associated risks emanating from the service providers to include, operational risks, strategic risks, intrinsic risks of atrophy and location. In the operational risks, BPO service providers could claim non-existence expertise and IT infrastructure. The strategic risks entail the provision of hidden costs that lead to exploitation of the client by the service provider through the use of profit maximisation as a business strategy. While the outsourcing clients outsource non-core services and focus on core competence, employed professionals could be made redundant within their respective business units in their organisation because of the knowledge transfer to the service provider. Another risk comes from change of location especially through offshore outsourcing relationships where cultural and language differences adversely affect services provided to clients.

In order to reduce these risks associated with outsourcing and improve performance at both the client and provider's domain, Kremic et al. (2006) presented an outsourcing decision framework to guide outsourcing clients. The framework specifically outlined the key factors to be considered before embarking in outsourcing of services - reasons for outsourcing, influential factors, and risks associated with outsourcing. Kremic et al., (2006) suggest that intending clients should, first of all evaluate these factors with the organisation's business objectives and if it portends a positive outcome, only then should the organisation outsource. Over the years clients have become victims of failed outsourcing relationships which researchers attributed to lack of IT infrastructure and its integration within a BPO service provider organisation. For example, customer's failure to avail financial services from Royal Bank of Scotland (RBS) was linked to unreliable application software used by their service provider in India in processing their services (Allen et al., 2012). A \$3.5 billion 
deal between Sainsbury's and Accenture quickly failed after launch due to reasons emanating from unreliable software within the IT supply chain which consequently caused a renegotiation of the deal (Willcocks et al., 2010). As identified earlier, application software is required to process client services, and over the years, research evidence as presented by Kraut and Streeter (1995) suggests that the reliability of application software hinges primarily on the development process. In other words, a successful development process must involve individuals with sufficient knowledge of the domain requirements and, in this case, BPO service provider organisations with specific expertise and years of experience in the financial sector developing its own application software. Having considered the above risks and failures, Feeny et al. (2005) assert that the choice of a service provider could determine how successful the relationship would be.

\subsection{Choosing a BPO service provider}

Clients exploring the potential benefits of outsourcing business processes need to examine carefully at their own goals and be clear about required supplier capabilities (Lacity et al., 2009; Kim et al., 2007). This implies that the first step in identifying potential suppliers is for a company to consider its own requirement. Researchers (Feeny et al., 2005; Weerakkody et al., 2003; Bharadwaj and Saxena, 2010) have indicated specific provider's competencies to include the size of the provider, strength of the IT infrastructure, domain expertise, webenabled technology for delivery and project management skills. In terms of size, large BPO service providers tend to have strong financial background and domain expertise but should be chosen with caution. They handle various business processes for more than one client and this includes competing business institutions (Daven, 2012). To be considered for selection, a service provider must demonstrate the strength of their IT infrastructure to process and deliver services vis-à-vis bandwidth, data centre, and software development team (Weerakkody et al., 2003; Panda, 2012). Another key capability is ability to demonstrate thorough understanding of the domain requirements and challenges through knowledge and expertise (Lahiri et al., 2012). A service provider should be innovative and be able to demonstrate flexibility in its approach even when client's requirement changes along the way (Feeny et al., 2005). By establishing these prerequisites, Bharadwaj and Saxena (2009) emphasise that an acceptable level of IT managerial skills is required to achieve the combined benefits of these capabilities. 


\subsection{Conceptual BPO-IT framework}

In the literature, providers' capabilities have been centered on IT and IT management components; and therefore termed as critical factors for a successful BPO relationship. It is around these critical factors that the BPO-IT framework is constructed. In the first instance, the IT components are identified as the application software required to process client services and then, the IT management component that provides the managerial skills for different IT functions. Figure 1 expresses the conceptual fit of these critical factors for BPOIT framework that could enhance performances. The "fit" is a measured level of combined IT components (identified as application software) and IT management skills adopted.

\section{$=====$ Figure $1===$}

\subsection{IT management}

In a service provider operating a BPO-IT organisational model, IT management skill is a key component for a successful outsourcing engagement. The objectives of investment in IT infrastructure could not be realised in the absence of IT management. McNurlin et al. (2009), describe IT management as the discipline whereby all of the technology resources of a firm are managed in accordance with its needs and priorities. In this case, these resources may include tangible investments like computer hardware, software, data, networks and data centre facilities as well as the staff hired to maintain them. IT management knowledge is an important capability of a service provider that enables the organisation to conceive, develop, and use firm-specific applications of IT that would improve process performance (Ray et al., 2004). The greater the complexity and interdependence of outsourced processes; the greater is the required level of technological advancement, investment and management in the process execution. Thus, in the absence of a strong IT leadership to coordinate business and processing teams, development of an enabling IT structure, both at the client and service provider, clients would be far from achieving their business goals (Martin et al., 2008). In BPO, without the involvement of the IT management team from the beginning of the BPO engagement process, it would be difficult to realise the strategic value for which the services were outsourced (Mani et al., 2010). This argument is consistent with the view of Tornbohm (2006) that business leaders of the outsourcing client or service 
provider must ensure that the IT manager is included in the executive team and associated decision making processes.

\subsection{IT components}

The IT components are determined by the client requirements and managed by the IT management team. These include computer hardware and software respectively. Within these components, the application software could be identified as a key component due to its effects on the quality of processed services delivered to clients. Kraut and Streeter (1995) are of the opinion that the quality of application software used in processing client services determines the quality of delivered services. Therefore, the process from which the application software evolved from would be of interest in this study. According to Sommerville (2011), to meet business opportunities, the application software development process must embrace rapid development and delivery. While Erickson et al. (2005) are of the view that agility should be a key component in the development process of the application software required for service processing. To add value to client's service, each outsourced business process is continuously encountering IT components, especially at the time of processing and delivery by the service provider.

\subsection{BPO performance}

The BPO performance is a result of the interaction between the combined IT components and IT management within the BPO-IT framework. BPO service providers perceive performance as the fulfilment of all client's requirement within the service level agreement (SLA) (Ikerionwu et al., 2014a) and thus "the accomplishment of a given task measured against pre-set known standards of accuracy, completeness, cost and speed" (Business Dictionary 2013). This could indicate that a service provider operating a BPO-IT framework may achieve the obligation(s) defined in the SLA more effectively and efficiently. SLA outlines the standard of performance, the method of calculating performance, specific client requirements, and mode of service delivery (Ikerionwu et al., 2014; Whitaker et al., 2011). Benefits associated with SLA include reduction of uncertainties, defining of all expectations including the acceptable level of processed service quality and mode of service delivery. However, to achieve desired performance, the service provider has to apply flexibility in its overall approach especially in the areas of development of software, service 
processing and SLA (Kremic, 2006; Sue et al., 2008). The next sub section discusses flexibility and its area of application in a conceptual framework.

\subsection{Flexibility}

Researchers have described flexibility as the ability to add value to clients' services through innovations, and re-engineering of applications to meet changing client requirements (Daven, 2012; Willcocks et al., 2004; Embleton and Write, 1998). At the time of software development, services processing, and delivery, innovations could be as a result of interactions between the IT components and IT management team primarily to add value to client services (Stauss and Jedrassczyk, 2008). Specific to business processes, Alagse (2011) defines flexibility as the ability of an organisation to effect changes in the process components such as its activities, technology, and information in a timely manner usually in response to changes in business environment, requirements and stakeholder needs. In the light of this, flexibility is an "add-on" component at the operational and technological levels (Golden and Powell, 2000; Infosys, 2012).

At the process level of a service, operational flexibility is conceptually described as the ability of a service provider to quickly provide new services based on changes in client requirements by adjusting an earlier business process solution template. It is often witnessed when service providers are faced with many clients requiring similar services. Providers tend to redesign the front-end user interface of the software primarily to provide privacy to client operations and attend to many clients simultaneously. Meanwhile, in every format, flexibility takes its root from technology. It is the ability of the technology to provide a platform for information processing in an organisation at any given time (Tushman and Nadler, 1978). Service providers are, therefore required to frequently upgrade their hardware, and people through training, in order to add value to client services.

Overall, clients could reduce risks associated with outsourcing by choosing service providers with required supplier's capabilities. On the other hand, providers must integrate IT into their organisation in order to attain the level of capability to qualify to be chosen by potential clients. Similarly, IT management and IT components were identified as the two critical factors in a BPO-IT organisation. The IT components involve the development process adopted within the conceptual BPO-IT framework in order to develop software with an acceptable level of quality. The entire process is managed by a strong IT management 
leadership and both client and provider's performances are tied to the combined levels of these factors. Generally, flexibility is a key factor for value creation and satisfaction of providers' numerous clients. The next section discusses the research methodology, data analysis, findings and discussion.

\section{Research methodology}

This study adopts an exploratory sequential mixed method approach, which as Cameron (2009) suggests, provides for an in-depth understanding of a phenomenon. A sequential abductive design is used (Leech and Onwuegbuzie, 2009), so the results of the qualitative study (Phase 1) formed the basis for further quantitative study (Phase 2), and has been applied in such areas like information systems (Themistocleous et al., 2004, Burke et al., 2007) and software engineering (Sjoberg et al., 2007). The findings in the exploratory study are derived from the triangulation of qualitative and quantitative results. The target population for this study is Indian BPO financial service providers that have been in operation for a minimum of 5 years and have offshore and onshore clients. India has maintained the number one position for outsourcing (Tholons, 2014, Javalgi et al., 2013) and is therefore an appropriate focus for the study. Firstly, through the largest umbrella of BPO service provider organisations in India - National Association of Software and Services Companies (Nasscom) and "BPO Watch India" websites, 180 BPO organisations providing financial services to offshore clients were identified. Their respective websites were visited for the very purpose of obtaining their contact details and more understanding of their service provisions. On identifying individuals of interest within these organisations, several exchange of emails and phone calls took place. It was identified that only 98 of these organisations are operating BPO-IT organisational model, and provide financial services to onshore and offshore clients. With further communications, seven organisations (represented as BPO1 to BPO7) satisfied the sample selection criteria to participate in the study. Among these, six organisations operate BPO-IT making the core sample of organisations.

\section{Phase 1}

Twelve participants were interviewed, two from each organisation. This is in line with previous works by Creswell $(2002,2007)$ and Guest et al., (2006). The researchers applied 
semi structured open-ended questions to systematically collect data from research participants and introduced flexible probing (Noor, 2008) for depth and richness within the context of BPO-IT throughout the interview. The interview questions are made up of 38 semi-structured questions distributed into the following sub-sections: background of BPO service providers (5), BPO process cycle (11), service providers' perception of BPO performance (6), and application software development and management of IT components (16). The interviews for BPO service providers were recorded with digital Dictaphone and saved as MP3 digital files. The captured interviews were transcribed to Microsoft Word documents. This data was imported to the NVivo version 10 software for coding and analysis of qualitative data. NVivo 10 was adopted for the research because of its advanced datahandling and manipulation features. It supports data management, data editing, and allows contextual annotation, importing and exporting of data to statistical packages. This combined the benefits of software and manual analysis (Weber, 1990; Blismas and Dainty 2003). There are three specific stages involved in the analysis:

1. The interview word document is imported into NVivo

2. This stage comprises assigning text units, generating nodes for each question, and indexing. This was followed by gathering and collecting codes for comprehensive analysis through filtered interview responses, cross case interview analysis, word frequency, text search query, and emerging categories.

3. Interpreting codes and outcomes from stage 2. This stage also categorised key words and phrases to form themes. The processes in stage 2 and 3 were repeated until new categories did not emerge. Further, the process of word frequency and text search query are discussed as follows:

Word frequency analysis

The words, which are considered useful and important in the cross case interview are coded question-by-question and stored in a tree-like structure. At this stage, word count or frequency analysis is applied through the use of query (Word Frequency) to identify the words that are predominantly discussed. Specifically, it is performed to determine the frequency of a word relative to the total words counted across interview of participants. The result is expressed in weighted percentages. The weighted percentage assigns a portion of 
the word's frequency to each word so that the overall total does not exceed $100 \%$ (Leech and Onwuegbuzie, 2011). In this study, to calculate the weighted percentage, the researchers set the maximum number of words to be displayed as 1000 with minimum characters of 4 .

Text search analysis

Text search query is used to identify the prevalent phrase, idea or words in participant's discussions. It is performed on the cross case interview to search for the usage of a word of interest within respondents interview (Leech and Onwuegbuzie, 2011). The result is expressed in percentage with specific value to each interviewee. When more than a word is searched for, the search is performed using the OR logic to include all related words and the result is expressed in weighted percentage.

\section{Phase 2}

In the second phase of the study, the quantitative approach was adopted. Through Nasscom and "BPO watch India" websites, 754 potential participants were identified. The researchers established communication with relevant individuals in these organisations and it was later found that only 380 BPO organisations provided financial services. This number represents a larger base of the target population (BPO service providers) when compared with the 7 service providers involved in the case study. A letter introducing the research study and a request letter to participate in the study were sent to relevant individuals within each organisation. The quantitative questions were in the form of an online questionnaire, which was developed based on the outcome of the qualitative analysis of the data collected, and intended to increase accuracy Malterud (2001). The questionnaire consists of 27 questions, including 4 Matrix and 1 Likert scale based question. The questions are distributed into 3 sub-sections, to be answered by individuals who contribute to the decision making within the IT department of the BPO service provider. These sub sections are discussed as follows:

1. Background of service provider: In this section, 5 questions (1-5) were asked to ascertain the conformity of the criteria set for service provider's background before the study could commence. This is consistent with the criteria which states that 
participating organisations must have been in outsourcing domain for a minimum of 5 years, has clients both onshore and offshore, and providing financial services.

2. Impact of IT on BPO performance: There are 9 questions, which were derived, based on the responses to the 17 questions asked to interviewees in the BPO process cycle and service provider' perception of performances of the qualitative case study. Thus, the responses from the quantitative study are used to corroborate the result of the qualitative result and expand the understanding of the impact of IT on BPO performance.

3. Development and management of IT components: There are 13 questions in this section of study which were condensed from 16 questions that comprised of application software development and management of IT components in the qualitative case study.

After obtaining participants consent, a link to the questionnaire was distributed to 358 potential participants. Participants were specifically requested to forward the questionnaire to the right person within the organisation if they do not hold any position relating to IT platform and service processing. Such positions include IT manager, Process leader, VP, project manager, and management level of the organisation.

After forty-four days, a total of 156 valid responses were received which represents $44 \%$ response rate. This value is consistent with Baruch and Holtom (2008) assertion that the average response rate required for studies at organisational level is $37.2 \%$. A total number of 128 of the 358 potential participants did not respond to the questionnaire, a further 74 responses were invalid because respondents did meet the position criteria, and some of the organisation's dates of establishment were below five years. In order to prepare the collected data for analysis, responses were initially assigned codes using a codebook and subsequently coded into SPSS software version 21.0. The statistical tools used for the analysis are Factor analysis, Cronbach's Alpha, correlation matrix, Kaiser-Meyer-Olkin Measure of sampling adequacy, and Bartlett's Test of Sphericity. 


\section{Findings and Discussion}

\section{Outsourcing process cycle}

The initial stage of the research was to profile the outsourcing process cycle in order to understand the component elements of the process and potential hot spots for managerial focus. The findings indicated that the outsourcing process cycle is initiated by the outsourcing client through the issuance of "request for information" (RFI) to potential service providers. The RFI contains what services the clients intend to outsource, their expectation from the provider and questions covering provider's capabilities. After understanding the client's requirement, service provider responds to RFI and the selection process commences. Firstly, to confirm the provider's capabilities and the level of risks they are exposed to, the participants affirmed that clients could independently investigate from other clients identified in the RFI returned by the service provider. For example, within the financial domain, clients who had earlier outsourced services to the same provider could be approached for advice and their personal experience with the potential provider. As indicated in table 2 clients confirm that these risks are not prevailing within the potential provider, they possess the capability, and also demonstrate competency in the delivery of similar services. Respondents indicated that clients request a physical demonstration of essential competencies as a prerequisite for further negotiation and eventual selection. This whole approach reflects a classic confirmation of providers' capabilities, the level of risks being exposed to, user requirements and service level agreement stance within a process cycle (table 2). Yet, the results in table 2 presents research participant responses to explaining what an outsourcing process cycle is, and a clear story as to how outsourcing is initiated, service outsourced, processed and delivered back to the client. Therefore, all the activities that take place from the time a service is outsourced, processed and delivered is termed as an "outsourcing process cycle".

\section{$=====$ Table $2=====$}

Table 2 indicates that the service provider's capabilities and associated risks are, first confirmed through physical inspection of site and independent investigation involving former or current clients of the provider. This is in addition to demonstration of understanding of client requirements and industry expertise. In the absence of requisite 
human resource, a selected service provider provides the lacking human resources by training of individuals who would conduct a "test run" of the service processing before the actual provision of service goes "live". From here on, a service level agreement (SLA) is signed, physical inspection undertaken, services are processed and delivered, daily contacts are maintained, and performance monitoring is established. This process corroborates Gewald et al. (2006) assertion that the method of provider's selection significantly affects the outcome of the outsourcing relationship. In effect, the choice of a service provider could be the beginning of a failed or successful outsourcing relationship.

In order to understand the most frequently used terminologies and its effect on the overall outsourcing relationship, the word frequency analysis was performed on the cross case interview which produced the following weighted values in percentage: capability $(2.04 \%)$, SLA $(1.75 \%)$, competence $(1.46 \%)$, requirements $(1.17 \%)$, training $(1.27 \%)$, inspection $(0.87 \%)$. The usage of these keywords by interviewees suggests that clients confirm providers' capabilities and competency through physical inspection before signing SLA with a provider. This result is a corroboration of the thematic findings presented in table 2 . It suggests that service providers sign SLA with a client but also consider client's requirements before providing services. The size of the service provider, available skills and its financial status are also considered before they are selected through open bidding. It is worthy to note that the information on risks assessment are contained in a copy of RIF and are independently investigated by the client. As indicated earlier, Feeny et al. (2005) assert that to be considered for selection, a service provider must demonstrate competency in domain knowledge and industry expertise. Concisely, the initial stages of a process cycle include assessment of risk factors within the provider, demonstration of capabilities and competency within the industry sector. The next section investigates IT management skill and application software identified as the two critical factors within a conceptual BPO-IT framework.

\subsection{IT management skill}

In order to understand the specific role of IT management, interviewees were asked to indicate the importance of IT management within their organisation. Interviewees identified IT management as a critical factor in a successful BPO relationship, this question was asked 
in order to understand the extent of IT management skill involvement in a process cycle. One of the interviewees indicated as follows:

"IT management is part of the overall cycle of planning. When I say planning, in a brief sense, I am talking about people, technology and process. People, yes; find good people and train them. The HR department handles this. Technology-technology is where the IT teams and latest IT equipment and techniques that is to be deployed come into effect" (IT manager, BPO1).

In the cross interview analysis, all the respondents indicated IT and IT management skill as key components in a process cycle.

\section{$====$ Figure $2====$}

In the wider quantitative study, responses in figure 2 shows that service providers considered all the provided options as critical but most significantly, IT and IT management (135). Others include system integration (92), delivery mode (84), and data management (27). This is an indication that in the absence of IT and IT management skill, service processing and delivery could not be feasible especially within a BPO-IT framework. Without IT enablement, BPO as a strategic option would not have been feasible (Batra, 2006). However, IT enablement without a strong IT management skill could be far from achieving the organisations' business goals (Park and Im, 2007). One of the IT components identified in the conceptual framework is the application software required to process client services. The next section investigates how organisations obtain this software.

\subsection{Application software acquisition}

In the cross interview analysis, all but BPO7 indicated that, within their organisation they develop the application software required to process client services. This suggests that six BPO service provider organisations are operating BPO-IT organisational model. Interviewees indicated that their respective organisations established dedicated software development teams exclusively for in-house software development. Research participants responded that their respective software development teams comprise of the following number of members: BPO1 (128), BPO2 (350), BPO3 (125), BPO4 (115), BPO5 (98), BPO6 (80), and 
BPO7 (not applicable). Figure 3 suggests that 98 BPO organisations acquire application software required to process client services through in-house software development, 24 purchase from a vendor, 28 obtain from client, while 11 outsource to IT Company.

\section{$====$ Figure $3===$}

Although investigation into the development process adopted by each development team is beyond the scope of this study, the researchers asked the participants to identify their respective development paradigm. As a follow up question, it could add credence to the "cut out" task of the software development team. Most respondents indicated the use of "Agile" but went further to say;

"It depends on client requirements after carrying out case study. Agile method combined with software reusable components commonly used" (Software developer, BPO4).

The text search analysis for the words "agile", "reusable", and "components" were performed using the OR logic condition (agile OR reusable OR components) on the cross interview of respondents, the following words usage were revealed: BPO1 (0.04\%), BPO2 (0.29\%), BPO3 (0.04\%), BPO4 (0.85\%), BPO5 (0.18\%), BPO6 (0.46\%), BPO7 (0.00\%). These suggest that all but BPO7 could develop application software using agile framework and reusable software components. The goal of using agile and reusable components is to quickly adapt to changes in client requirements and improve the software quality. (Bertoa et al., 2003; Sommerville, 2011). Most BPO organisations obtain their software through inhouse development because software acquisition through vendors or sub-contracting to IT companies could not be easily "fine-tuned" to solve specific issues emanating from frequent changes in clients' requirements (Ikerionwu et al., 2014b). In doing so, they aim to reduce the processing costs and improve the quality of services delivered to clients. As indicated earlier, the provision of application software through in-house development is only feasible in a BPO-IT organisational model, thus interviewees were specifically asked to state the benefits of operating BPO-IT model. The next section, therefore, presents the benefits of BPO-IT organisational model. 


\subsection{Reasons for operating BPO-IT organisational model}

Primarily BPO-IT provides the platform for in-house provision of IT functions required to process and deliver services to clients. To understand why some BPO organisations have chosen to operate a BPO-IT model, respondents were specifically asked; what can you say are the gains of integrating IT into BPO? Table 3 presents the themes derived from cross interview analysis of research participants.

\section{$====$ Table $3===$}

From table 3, interviewees' suggested the following reasons: quick turnaround time; maintaining confidentiality of client's operations; delivery of SLA within a short time; expanding the scope of engagement; reduction in service processing cost; competitive edge and finally, quality software that is translated to quality services. The word frequency analysis shows the following weighted percentages: cost (5\%), quick (5\%), competitiveness (2.5\%), protected $(2.5 \%)$, operations $(2.5 \%)$, and improved $(2.5 \%)$. This suggests that the cost of processing services is reduced when a service provider develops the software required to process client services. When the turnaround time is quickly reduced, it implies that SLA is quickly achieved. The fear of stealing intellectual property by exposing client operation to rival organisations is significantly reduced when a service provider provides the application software in-house. The involvements of a third party organisation for the provision of software implies that they would first, understand the client's requirement before the development of the software. In effect, organisations that operate BPO-IT could enhance client's performances, improve quality of services, provide privacy to clients operations and reduce cost of services. This is in line with researchers (Bharadwaj and Saxena, 2010; Singh, 2012) assertion that providers stand a chance of being selected if they could demonstrate that required IT functions for service processing and delivery could be provided in-house. Overall, client competitiveness is improved and enhanced quality services are delivered to client's primary customers. For a wider investigation and understanding, the researchers reached out to a wider number of organisations through a questionnaire and the result is presented in the next subsection. 


\section{Questionnaires}

Based on the thematic findings in the qualitative phase, the reasons for operating BPO-IT were presented to participants in the form of a matrix question with Likert scale.

If you develop software in-house, indicate your level of agreement with each of the six possible reasons for doing so. (where 1= strongly agree; 2 = agree; 3 = disagree; 4 = strongly disagree).

The options for the selection include six components; competitive edge, job security, retaining IT jobs, reduces turnaround time, provides secrecy over clients operation, and reduces processing cost. To analyse the matrix question, Factor analysis was considered but subject to fulfilment of criteria for the adoption of factor analysis. In the first instance, the 156 valid variables as responses from participants were condensed to a manageable level of numbers, followed by the establishment of correlation between the six components. This process is in line with Pallant (2010) assertion that factor analysis is suitable for data reduction, testing for validity and reliability of the variables, and establishing the correlation of the study components and as per previous studies in the field (Tariq and John, 2000, Tabachnick and Fidell 2007).

For suitability of factor analysis, the correlation matrix should show at least some correlation of $r=0.3$ or more (Pallant, 2010). In the correlation matrix in table 4 , there are nineteen number of correlations of more than 0.3 value which are expressed in bold figures. This significant level of correlation between the six thematic components indicate that each of the components contribute significantly towards an acceptable level of client's performance.

\section{$===$ Table $4===$}

Kaiser-Meyer-Olkin (KMO): The KMO test value is considered significant at 0.6 or above. In this case, the value is 0.735 . The value of the Bartlett's test of Sphericity is 0.000 . The significant value is $p<0.05$ (Bartlett, 1954). In the above instances, the six components satisfied the criteria for the use of factor analysis. 
$====$ Table $5===$

\section{Factor extraction}

Thompson (2004) suggests that factor analysis is used to determine the smallest number of factors or components that are required to represent the interrelationship among a set of variables. To extract these variables, Thompson suggested that principal component analysis (PCA) is the default method in most statistical analysis. In PCA, three principal techniques (Kaiser's criterion test; Scree plot test; and Parallel analysis test) are applied to determine the number of factors to retain and study further.

\section{$====$ Table $6===$}

When the six components were subjected to Kaiser criterion's test (table 6), only two of the returned components have eigenvalues more than 1 (2.972 and 1.441). According to Pallant (2010), the extracted components with eigenvalue $=>1$ are to be selected for further investigation. The cumulative $\%$ of the two components returned a total of $75 \%$ (49\%.53, $24.023 \%$ ) which suggests the retention of a two component solution. To further confirm the two components solution, the Scree test was performed on the six components. The Scree test plot returned two components with eigenvalues of more than 1 which are further supported by the results of the Parallel analysis which returned two components after the comparison of eigenvalues from PCA and Kaiser's criterion values from parallel analysis. This suggests further investigation of these two components.

\section{$====$ Table $7====$}

In support of the interpretation of the two components solution, an Oblimin rotation was performed as shown in table 7 . The rotation solution revealed the presence of simple structure (Thurstone, 1947), with both components showing a number of strong loadings and all items loading substantially only on one component respectively. The strong loadings in each component are in presented in bold to highlight their presence and its level of importance among the reasons for in-house software development through BPO-IT organisational model. This interpretation suggests the level of consistency with the responses from the interviewees which show the scale of importance of each variable in relation to in-house development of application software. Based on the six thematic components identified in the qualitative study, the factor analysis (table 7) indicates that BPO organisations develop application software in-house for the following reasons in the 
order of importance: reduces turnaround time (0.876); reduces service processing cost (0.873); competitive edge (0.872); retains IT jobs (0.864); confidentiality to clients operations (0.844); and job security (0.806).

The above interpretation supports the call for the need to develop a conceptual framework that could help in mitigating the risks and failures associated with BPO (Saxena and Bharadwaj, 2009). As suggested by practitioners and academic (Weerakkody et al., 2003; Singh, 2012), investment in IT infrastructure and its integration into a BPO service provider organisation would provide an enabling platform to improving performances and reducing failures in a BPO relationship. By implementing BPO-IT organisational model, service providers would, internally, determine the quality of application software required to process client services. Consequently, the quality of service delivered to clients is improved (Galin, 2004; Grover et al., 1996). They would be more competitive (including their clients), services are received and processed within a short time, and services are provided at a reduced cost. The provision of IT functions that would have been outsourced to IT companies are retained within the organisation, thereby improving the organisation's retention of IT job. When IT functions are outsourced to a third party, there are increased chances or leaking client's requirements and operation to the potential provider. In contrary, service provider's in-house software provides confidentiality against the "prying eyes" of client's competitors.

\subsection{Derivation of BPO-IT framework}

The service provider's BPO-IT framework comprises the IT components within the IT framework of a service provider operating a BPO-IT organisational model. However, the scope of this paper has been limited to the provision of application software as one of the IT components. Figure 4 represents a BPO-IT framework of a service provider derived from the combined analysis of qualitative and quantitative data. In the figure, there is an outsourcing relationship depicted with a bidirectional arrow and labelled "outsourcing relationship". The relationship is between an outsourcing client and a service provider represented as a block labelled "BPO service provider".

The conceptual framework (figure 1) and research participants in figure 2 identified IT and IT management as critical factors in a BPO relationship. While describing what a process cycle 
is, interviewees also maintained that they must demonstrate IT and its management capability in order to be selected by a client. This perception confirms Kim et al. (2007) assertion that the adoption of IT intensive BPO could be well measured by the level of IT maturity, which includes IT management skills, infrastructure and innovative culture. Client's BPO requirements are IT enabled services and a provider must show capability and competence in both IT and IT management that would add value to delivered services (Feeny et al., 2005; Saxena and Bharadwaj, 2009). Thus, based on the overall study, the processing and delivering of client services by a service provider involves constant interaction of six specific components presented in figure 4. These components are identified as: IT management, software development team, development process (i.e. agile and reusable software components), flexibility, and service processing and delivery. The constant interaction is depicted by a bidirectional arrow between components.

\section{$===$ Figure $4===$}

When a client outsources a business process to a provider, if the required software for processing the service is not available within the IT components, the IT manager interacts with the software development team, purposely to develop the software. In a process cycle, interviewees indicated that clients' requirements are considered before services could be processes. Thus the development team considers client requirements and adopt an appropriate development process that would provide an acceptable level of software quality. In this case, the interviewees indicated that their development team used agile development framework and reusable software components. Agile development provides an enabling platform for team members to quickly adjust to varying client requirements, thereby improving the software quality (Dyba and Dingsoyr, 2015).

The developed software is delivered to the service processing team to process client services. At this level, the processing team would employ a flexible approach in order to provide service with an acceptable level of quality. The primary reason is to add value to client's services (Stauss and Jedrassczyk, 2008). It could be through technological and operational flexibilities whereby team members quickly learn how to use the new software and its technological underpinnings. Feeny et al. (2012) described flexibility as one of the capabilities a service provider must show competency in a BPO relationship. In this way, services are processed and delivered to clients. 
As an indication of reducing the risks associated with outsourcing (table 1), clients strictly follow the steps interviewees stated in table 2 and when a provider is chosen, there is frequent visits to the provider by the client, daily communications, performance measuring and monitoring systems are established. Frequent contacts and daily communications build emotional bonds between clients and providers, thereby forestalling problems that could hinder the outsourcing relationship (Lo et al., 2007).

\section{Conclusions}

This study developed a BPO-IT framework for a service provider operating a BPO-IT organisational model. The framework identified IT and IT management skills as critical factors required for establishing and managing the framework. The key elements within the framework include the IT manager, software development team, service processing, IT components, and flexibility as the key elements. Failures in BPO relationships could be reduced through the implementation of the developed BPO-IT framework. It enhances both client and provider's performances in the following specific areas:

- Reduced cost of processing services

- Improved service quality

- Reduced turnaround time in processing of services

- Improved competitiveness

- Provides confidentiality to client operations

To reduce risks associated with outsourcing, participants suggest that it is on the client interest to apply open bidding in provider's selection while adhering to the following steps:

- Clients should independently verify provider's claim in RFI.

- Providers should demonstrate IT capability and competency within the industry domain.

- Frequent physical visit and communication could provide an honest bond that would improve the relationship

These steps when collectively implemented could improve providers' selection process and improve chances for success, as a flawed selection process is the foundation of failure in outsourcing relationship (Huang and Liao 2008). 


\section{Limitations and Further Research}

The scope of this study has been limited to the development of a BPO-IT framework and identifying its critical components. The in-house provision of software as an IT function is only a unit of the total IT components within a BPO-IT organisation. Therefore, its benefits are also restricted to in-house sourcing of software using the BPO-IT framework. Further research could be performed to understand the software development process that could provide software with an acceptable level of quality that would improve client performances.

Secondly, the sample size of seven BPO service providers and a larger 156 is a potential concern. Though the samples are within the acceptable sample sizes but it is relatively smaller than the researchers would have preferred. This has made it difficult to generalise the findings in the broader BPO domain. There are other industry sectors involved in BPO, but the scope of this investigation has been restricted to financial service providers. As such, the claims in this study have been confined to an exploratory study that would have produced a generalisable claim with more data.

\section{References}

Allen, V., Barrow, B. and Salmon, J. (2012). Did one high-tech worker bring RBS to its knees? Retrieved June 14, 2014, from http://www.dailymail.co.uk/news/article-2165202/DidONE-high-tech-worker-bring-RBS-knees-Junior-technician-blamed-meltdown-frozemillions-accounts.html

Aron, R., Clemons, E. and Reddi, S. (2005). Just right outsourcing: understanding and managing risk. Journal of Management Information Systems, 22(2), 37-55.

Axelrod, C. (2004). Outsourcing information security. Boston: Artech House.

Bartlett, M.S. (1954). A note on multiplying factors for various chi-squared approximations. Journal of the Royal Statistical Society, 16, 296-298.

Baruch, Y. and Holtom, B. C. (2008). Survey response rate levels and trends in organizational research. Human Relations, 61(8), 1139-1160.

Batra, S. (2006). Impact of information technology on organizational effectiveness: a conceptual. Global Journal of Flexible Systems, 7(1/2), 15-25.

Bertoa, M. F., Troya, J. M. and Vallecillo, A. (2003, July). A survey on the quality information provided by software component vendors. In Proceedings of the 7th ECOOP Workshop on Quantitative Approaches in Object-Oriented Software Engineering (QAOOSE) (pp. 2530). 
Bharadwaj, S. and Saxena, K. (2009). Building winning relationships in business process outsourcing services. Industrial Management and Data Systems, 109(7), 993-1011.

Bharadwaj, S. and Saxena, K. (2010). Service providers' competences in business process outsourcing for delivering successful outcome: an exploratory study. Vikalpa: The Journal for Decision Makers, 35(3), 37-53.

Blismas, N. G. and Dainty, A. R. (2003). Computer-aided qualitative data analysis: panacea or paradox? Building research and information, 31(6), 455-463.

Burke, J. R., Onwuegbuzie, A. J. and Turner, L. A. (2007). Toward a definition of mixed methods research. Journal of Mixed Methods Research, 1(2), 112-133.

Business Dictionary. (2012). Definition-performance. Available at: http://www.businessdictionary.com/definition/performance.html [Retrieved June 28, 2013]

Cameron, R. (2009). A sequential mixed model research design: design, analytical and display issues. International Journal of Multiple Research Approaches, 3(2), 140-152.

Clemons, E. K., Reddi, S. P. and Row, M. C. (1993). The impact of information technology on the organization of economic activity: The move to the middle hypothesis. Journal of management information systems, 9-35.

Click, R. and Duening, T. (2005) Business Process Outsourcing: The Competitive Advantage. Wiley and Sons, Hoboken, NJ.

Daven, M. (2012, May 21). How to Choose the Right Business Process Outsourcing Companies? Available at: http://bridge-outsourcing.com/how-to-choose-the-rightbusiness-process-outsourcing-companies. [Retrieved on September 29, 2014]

Dyba, T. and Dingsoyr, T. (2015, May). Agile project management: from self-managing teams to large-scale development. In Software Engineering (ICSE), 2015 IEEE/ACM 37th IEEE International Conference on (Vol. 2, pp. 945-946). IEEE.

Embleton, P. and Wright, P. (1998). A practical guide to successful outsourcing, Empowerment in Organizations, 6(3), 94.

Erickson, J., Lyytinen, K. and Siau, K. (2005). Agile modeling, agile software development, and extreme programming: the state of research. Journal of Database Management, 16(4), 88-100.

Feeny, D., Lacity, M. and Willcocks, L. (2005). Taking the measure of outsourcing providers. MIT Sloan Management Review, 46(3), 41-48.

Feeny, D., Lacity, M. and Willcocks, L. P. (2012). Taking the measure of outsourcing providers. MIT Sloan management review, 46(3).

Galin, D. (2004). Software quality assurance: from theory to implementation. Pearson education. 
Gewald, H., Wüllenweber, K. and Weitzel, T. (2006). The Influence of perceived risks on banking managers' intention to outsource business processes: A study of the German banking and finance industry, Journal of Electronic Commerce Research, 7(2), 78-95.

Golden, W. and Powell, P. (2000). Towards a definition of flexibility: In search of the Holy Grail? Omega, 28(4), 373-384.

Grover, V., Cheon, M. J., and Teng, J. T. (1996). The effect of service quality and partnership on the outsourcing of information systems functions. Journal of Management Information Systems, 89-116.

Gyeung-Min, K. (2008).E-business strategy in Western Europe: offshore BPO model perspective. Business Process Management Journal, 14(6), 813-828.

Huang, L. and Liao, X. (2008, September). An Analytic Network Process Model for Selecting Vendors in Business Process Outsourcing. In Advanced Management of Information for Globalized Enterprises, 2008. AMIGE 2008. IEEE Symposium on (pp. 1-5). IEEE.

Ikerionwu, C., Foley, R. and Gray, E. (2014b). Improving software quality in the service process industry using agility with software reusable components as software product line: An empirical study of Indian service providers. International Journal of Advances in Engineering \& Technology, 7(3), 701.

Ikerionwu, C., Foley, R., Gray, E., and Edgar, D. (2014a). Business process outsourcing service providers' perception of performance and performance measurement. Journal of Economics \& Engineering, 5(2).

Infosys Finnacle. (2012). Standard Bank Namibia launches new core banking system Retrieved June 12, 2013, from http://www.infosys.com/finacle/mediaroom/pressreleases/Pages/press-release-core-banking-system.aspx

Javalgi, R., Joseph, W., Granot, E. and Gross, A. (2013).Strategies for sustaining the edge in offshore outsourcing of services: The case of India. Journal of Business, 28(6), 475-486.

Karmarkar, U. (2004). Will you survive the services revolution? Harvard Business Review, 82(6): 101-107.

Kim, G. M. and Jung Won, H. (2007). HR BPO service models for small and medium enterprises. Business Process Management Journal, 13(5), 694-706.

Kraut, R. and Streeter, L. (1995). Coordination in software development. Communication of ACM, 38(3), 69-81.

Kremic, T., Tukel, O. and Rom, W. (2006). Outsourcing decision support: a survey of benefits, risks, and decision factors. Supply Chain Management: An international Journal, 11(6), 467-482.

Lacity, M. and Willcocks, L. (2012). Advanced outsourcing practice. Houndmills, Basingstoke, Hampshire: Palgrave Macmillan. 
Lacity, M., Khan, S. and Willcocks, L. (2009). A review of the IT outsourcing literature: Insights for practice. The Journal of Strategic Information Systems, 18(3), 130-146.

Lacity, M., Solomon, S., Yan, A. and Willcocks, L. (2011). Business process outsourcing studies: a critical review and research directions. Journal of information technology, 26(4), 221-258.

Lahiri, S., Kedia, B. L. and Mukherjee, D. (2012). The impact of management capability on the resource-performance linkage: Examining Indian outsourcing providers. Journal of World Business, 47(1), 145-155.

Leech, N. L. and Onwuegbuzie, A. J. (2009). A typology of mixed methods research designs. Quality and Quantity, 43(2), 265-275.

Leech, N. L. and Onwuegbuzie, A. J. (2011). Beyond constant comparison qualitative data analysis: Using NVivo. School Psychology Quarterly, 26(1), 70-74.

Li, H. and Zhang, H. (2007). Outsourcing Risks Analysis: A Principal-Agent Theory-Based Perspective. Advances in Multiple Criteria Decision Making and Human Systems Management: 195.

Linder, J., Cantrell, S. and Crist, S. (2002). Business Process Outsourcing Big Bang: Creating Value in an Expanding Universe. Accenture Institute for Strategic Change Research Report. Cambridge, MA. July

Lo, L. C. and Chung, W. W. (2007). A study of outsourcing relationship in strategic partnership for production in China. International Journal of Logistics Systems and Management, 3(3), 288-304.

Loh, L. and Venkatraman, N. (1992), Determinants of information technology outsourcing: a cross sectional analysis. Journal of Management Information Systems, 9(1), 7-24.

Mahmoodzadeh, E., Jalalinia, S. and Nekui, F. (2009). A business process outsourcing framework based on business process management and knowledge management. Business Process Management Journal, 15(6), 845-864.

Malterud, K. (2001). Qualitative research: standards, challenges, and guidelines. The lancet, 358(9280), 483-488.

Mani, D., Barua, A. and Whinston, A. (2006). Successfully governing business process outsourcing relationships. MIS Quarterly Executive, 5(1), 15-29.

Mani, D., Barua, A. and Whinston, A. (2010). An empirical analysis of the impact of information capabilities design on business process outsourcing performance. Management Information Systems Quarterly, 34(1), 5

Martin, S. F., Beimborn, D., Parikh, M. A. and Weitzel, T. (2008, January). Organizational readiness for business process outsourcing: a model of determinants and impact on outsourcing success. In Hawaii International Conference on System Sciences, Proceedings of the 41st Annual (pp. 374-374). IEEE. 
Mclvor, R., McCracken, M. and McHugh, M. (2010). Creating outsourced shared services arrangements: Lessons from the public sector. European Management Journal, 29(6), 448-461.

McNurlin, B., Ralph, H. and Sprague, H. (2009). Information Systems Management in Practice. Prentice-Hall International.

Michell, V. and Fitzgerald, G. (1997). The IT outsourcing market-place: vendors and their selection. Journal of Information Technology, 12(3), 223-237.

Overby, S. (2003). The hidden costs of offshore outsourcing. CIO-FRAMINGHAM MA, 16(22), 60-66.

Pallant, J. (2010). SPSS survival manual: A step by step guide to data analysis using SPSS. Berkshire: Open University Press.

Panda, A. (2012). Business process outsourcing: a strategic review on Indian perspective. Business Process Management Journal, 18(6), 876-897.

Park, J. Y. and Im, K. (2007). The role of IT human capability in knowledge transfer process under IT outsourcing situations. AMCIS 2007 Proceedings, 216.

Ray, G., Barney, J.B. and Muhanna, W.A. (2004). Capabilities, business processes, and competitive advantage: choosing the dependent variable in empirical tests of the resource-based view, Strategic Management Journal, 25(1), 23-7.

Reitzig, M. and Wagner, S. (2010). The hidden costs of outsourcing: evidence from patent data. Strategic Management Journal, 31(11), 1183-1201.

Saxena, K. B. C. and Bharadwaj, S. S. (2009). Managing business processes through outsourcing: a strategic partnering perspective. Business Process Management Journal, 15(5), 687-715.

Singh, S. (2012). IT-BPO combined model shows cracks yet HCL, Infosys and other IT majors believe that's the way to go corporate trends. The Economic Times (Online), Available at: http://search.proquest.com/docview/921642709?accountid=15977._[Retrieved on $14^{\text {th }}$ March, 2012].

Sjoberg, D. I., Dyba, T. and Jorgensen, M. (2007, May). The future of empirical methods in software engineering research. In 2007 Future of Software Engineering (pp. 358-378). IEEE Computer Society.

Sommerville, I. (2011). Software engineering ( $9^{\text {th }}$ Ed.) Harlow, England: Addison-Wesley.

Sue G. P., Greenberg, R. H. and Lederer A., Y. (2008). The role of trust in the governance of business process outsourcing relationships: $A$ transaction cost economics approach. Business Process Management Journal, 14(5), 593-608.

Stauss, B. and Jedrassczyk, M. (2008). Business Process Outsourcing (BPO): Value Creation through External Service Providers. Journal of Applied Management and Entrepreneurship, 13(3), 20-34. 
Tabachnick, B.G. and Fidell, L.S. (2007). Using multivariate statistics (5th edn). Boston: Pearson Education.

Tariq, S.A. and John, G.E. (2000). Identifying root causes of construction accidents. Journal of Construction Engineering Management, 126(1), 52-60.

Themistocleous, M., Irani, Z. and Love, P. E. (2004). Evaluating the integration of supply chain information systems: A case study. European Journal of Operational Research, 149(2), 393-405.

Tholons Research (2013). 2014 Top 100 Outsourcing Destinations. Available at: http:// http://www.tholons.com/nl_pdf/Whitepaper_December_2013.pdf. [Retrieved on $17^{\text {th }}$ February, 2014].

Thompson B. (2004). Exploratory and confirmatory factor analysis: understanding concepts and applications. Washington, DC: American Psychological Association.

Thurstone, L.L. (1947). Multiple factor analysis. Chicago: University of Chicago Press.

Tornbohm, C. (2006). Include the CIO when planning BPO, Gartner Research, July.

Tushman, M. L. and Nadler, D. A. (1978). Information processing as an integrating concept in organizational design. Academy of Management Review, 3(3), 613-624.

Weber, R. P. (1990). Basic content analysis, quantitative applications in the social sciences. Sage Publications, Inc., Beverly Hills, CA, 19, 24-26.

Weerakkody, V., Currie, W. and Ekanayake, Y. (2003). Re-engineering business processes through application service providers: Challenges, issues and complexities. Business Process Management Journal, 9(6), 776-794

Whitaker, J., Kumar, S. and Krishnan, M. S. (2011). Cost, Quality and Time Outcomes of Onshore and Offshore Business Process Outsourcing. In AMCIS.

Willcocks, L. (2010). The next step for the CEO: Moving IT enabled services outsourcing to the strategic agenda. Strategic Outsourcing: An International Journal, 3(1), 62-66.

Willcocks, L., Cullen, S. and Craig, A. (2010). The Outsourcing enterprise: From cost management to collaborative innovation. Basingstoke: Palgrave Macmillan.

Willcocks, L., Hindle, J., Feeny, D. and Lacity, M. (2004). IT and business process outsourcing: The knowledge potential. Information systems management, 21(3), 7-15.

Yang, D. H., Kim, S., Nam, C. and Min, J. W. (2007). Developing a decision model for business process outsourcing. Computers \& Operations Research, 34(12), 3769-3778. 